\title{
Reoperation for nonobstructive hypertrophic cardiomyopathy in a patient with extreme septal thickness
}

Daokun Sun, MD, MPH, ${ }^{\mathrm{a}}$ Hartzell V. Schaff, $\mathrm{MD},{ }^{\mathrm{a}}$ and Rick A. Nishimura, $\mathrm{MD}^{\mathrm{b}}$

Video clip is available online.

A 24-year-old male patient with familial hypertrophic cardiomyopathy presented with New York Heart Association class III heart failure. Two years earlier, he had undergone transaortic septal myectomy at another institution to relieve left ventricular outflow tract obstruction. However, his heart failure symptoms did not improve. On evaluation at our Clinic, transthoracic echocardiography confirmed nonobstructive hypertrophic cardiomyopathy. There was no left ventricular outflow tract gradient, but the left ventricular cavity size was small and the interventricular septum measured $48 \mathrm{~mm}$ (Figure 1, A). Left ventricular (LV) ejection fraction was $84 \%$, and $\mathrm{LV}$ stroke volume index was $37 \mathrm{~mL} / \mathrm{m}^{2}$.

Transapical myectomy was performed to enlarge the LV cavity and eliminate any potential midventricular obstruction. $^{1-3}$ After the procedure, LV end-diastolic dimension increased from 30 to $43 \mathrm{~mm}$ (Figure 1, B), and cardiac index as estimated from transthoracic echocardiography increased from 2.7 to $3.4 \mathrm{~L} / \mathrm{min} / \mathrm{m}^{2}$ (Video 1). The patient recovered well and was discharged on postoperative day 6 .

Review by the institutional review board is not required. Informed consent has been obtained.

\footnotetext{
From the Departments of ${ }^{\mathrm{a} C a r d i o v a s c u l a r}$ Surgery and ${ }^{\mathrm{b}}$ Cardiovascular Medicine, Mayo Clinic, Rochester, Minn.

Disclosures: The authors reported no conflicts of interest.

The Journal policy requires editors and reviewers to disclose conflicts of interest and to decline handling or reviewing manuscripts for which they may have a conflict of interest. The editors and reviewers of this article have no conflicts of interest.

This work was supported by the Paul and Ruby Tsai Family.

Received for publication April 28, 2021; accepted for publication April 28, 2021; available ahead of print May 4, 2021.

Address for reprints: Hartzell V. Schaff, MD, 200 First St SW, Rochester, MN 55905

(E-mail: schaff@mayo.edu).

JTCVS Techniques 2021;8:71-2

2666-2507

Copyright (C) 2021 The Author(s). Published by Elsevier Inc. on behalf of The American Association for Thoracic Surgery. This is an open access article under the CC BY-NC-ND license (http://creativecommons.org/licenses/by-nc-nd/4.0/).

https://doi.org/10.1016/j.xjtc.2021.04.030
}

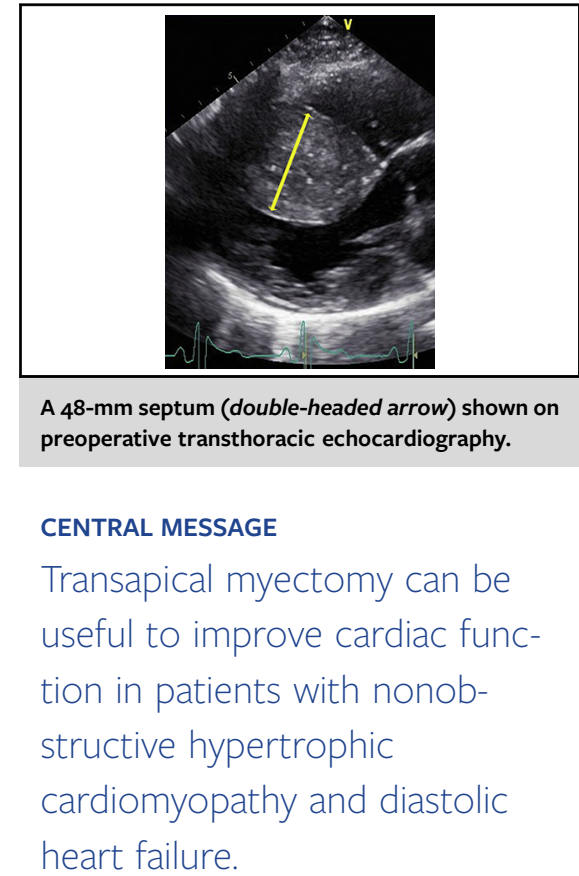

See Commentaries on pages 73 and 75 .

\section{References}

1. Schaff HV, Brown ML, Dearani JA, Abel MD, Ommen SR, Sorajja P, et al. Apical myectomy: a new surgical technique for management of severely symptomatic patients with apical hypertrophic cardiomyopathy. J Thorac Cardiovasc Surg. 2010; 139:634-40.

2. Nguyen A, Schaff HV, Nishimura RA, Geske JB, Dearani JA, King KS, et al. Apical myectomy for patients with hypertrophic cardiomyopathy and advanced heart failure. J Thorac Cardiovasc Surg. April 5, 2019 [Epub ahead of print].

3. Kunkala MR, Schaff HV, Nishimura RA, Abel MD, Sorajja P, Dearani JA, et al Transapical approach to myectomy for midventricular obstruction in hypertrophic cardiomyopathy. Ann Thorac Surg. 2013;96:564-70. 

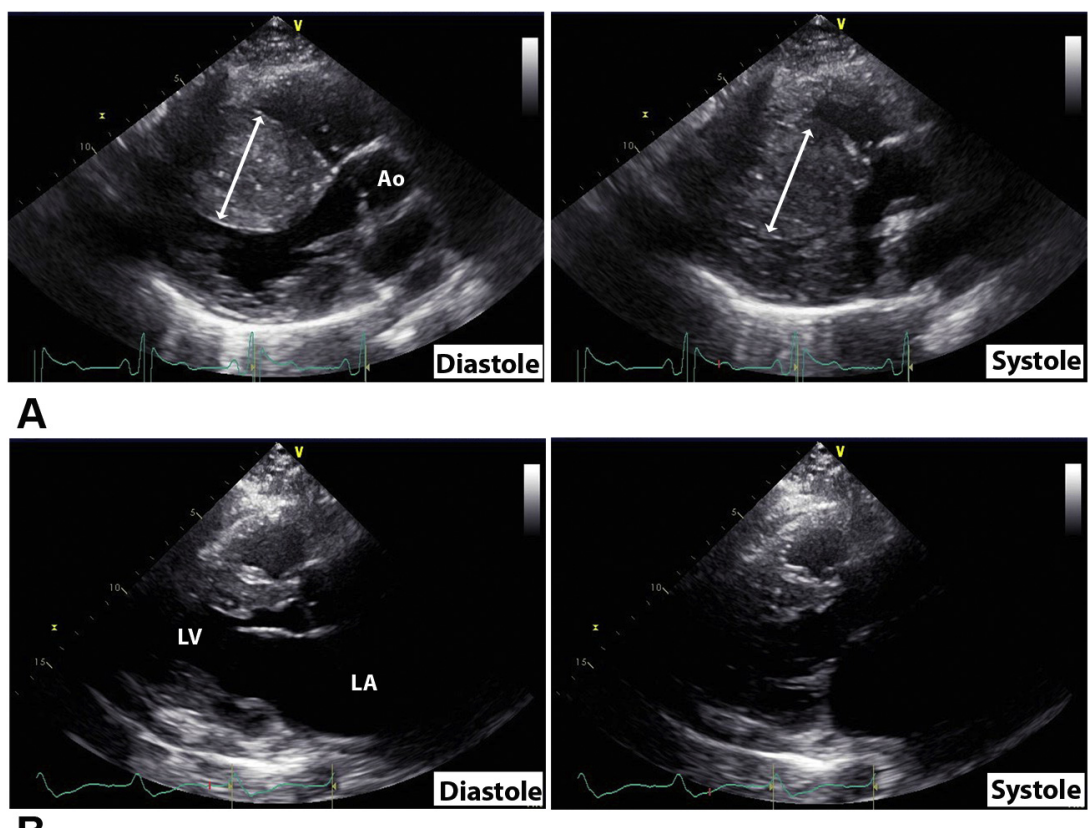

B

FIGURE 1. Parasternal long-axis view of the preoperative transthoracic echocardiogram (A) demonstrated a small left ventricular cavity with a maximum septal thickness of $48 \mathrm{~mm}$ (double-headed arrows). The LV cavity was significantly enlarged after transapical myectomy (B). Ao, Aorta; $L V$, left ventricle; $L A$, left atrium.

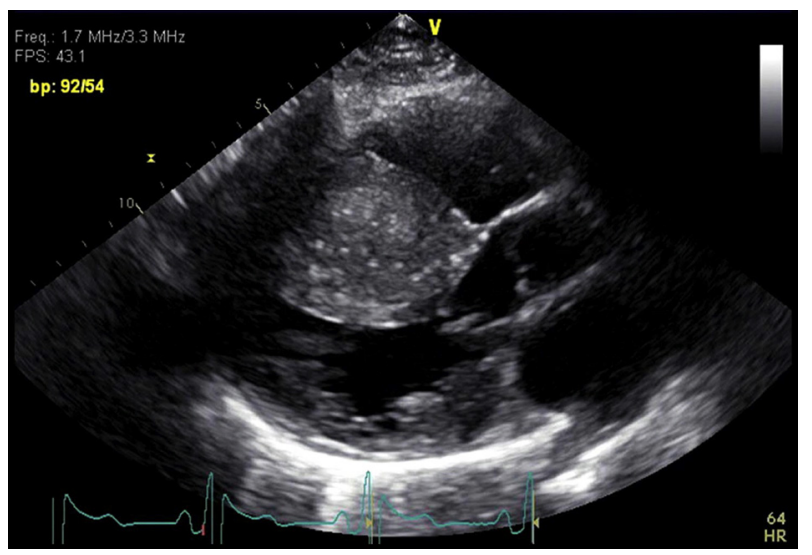

VIDEO 1. Parasternal long-axis view of preoperative and postoperative transthoracic echocardiogram. Video available at: https://www.jtcvs.org/ article/S2666-2507(21)00325-4/fulltext. 